\title{
Multiple Biliary Hamartomas Mimicking Diffuse Liver Metastases
}

\author{
Boris Guiu ${ }^{a}$ Séverine Guiu ${ }^{b} \quad$ Romaric Loffroy ${ }^{a} \quad$ Jean-Pierre Cercueil ${ }^{a}$ \\ Denis Krauséa \\ ${ }^{a}$ Department of Radiology, University Hospital of Dijon, and ${ }^{b}$ Department of Oncology, Georges-François Leclerc \\ Anticancer Center, Dijon, France
}

A 53-year-old woman underwent a stereotactic core biopsy of a spiculated mass discovered in her left breast during a systematic mammography. Histopathological examination demonstrated moderately differentiated invasive ductal carcinoma. A liver ultrasonography was performed during pretherapeutic evaluation and showed within both lobes multiple hypoechoic nodules highly suspicious of diffuse liver metastases. A subsequent magnetic resonance examination performed with cholangiography (fig. 1) revealed multiple irregularly-delineated hyperintense cystic lesions all measuring $<1.0 \mathrm{~cm}$ in diameter, not communicating with the biliary tree. These features were pathognomic of multiple biliary hamartomas (von Meyenburg complexes), which are small benign focal developmental lesions of the liver, pathologically consisting of collections of duct-like structures, dilating to varying degrees, lined by biliary epithelium set in an abundant fibrous stroma. The initial diagnosis of diffuse liver metastases was then definitely ruled out, leading to the curative surgical treatment of her early breast cancer. No recurrence or metastasis occurred within the following 2 years.

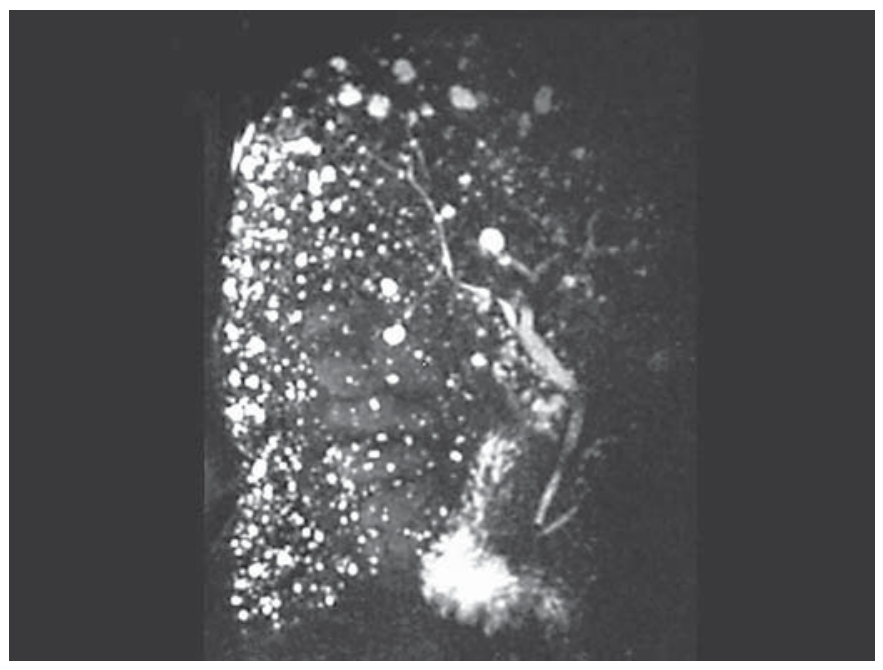

Fig. 1. Magnetic resonance cholangiography showing multiple biliary hamartomas.

\section{KARGER}

Fax +41613061234 E-Mail karger@karger.ch www.karger.com
(C) 2009 S. Karger AG, Base

0253-4886/09/0263-0209\$26.00/0

Accessible online at:

www.karger.com/dsu
Boris Guiu

Department of Radiology, Le Bocage University Hospital

Bd Maréchal de Lattre de Tassigny, FR-21000 Dijon (France)

Tel. +33 38029 3686, Fax +33 380295455

E-Mail boris.guiu@chu-dijon.fr 